\title{
Effects of Radiofrequency Electromagnetic Radiation on Neurotransmitters in the Brain
}

\author{
Cuicui $\mathrm{Hu}^{1,2}$, Hongyan $\mathrm{ZuO}^{2 *}$ and Yang $\mathrm{Li}^{1,2 *}$ \\ ${ }^{1}$ Anhui Medical University, Academy of Life Sciences, Hefei, China, ${ }^{2}$ Department of Experimental Pathology, Beijing Institute \\ of Radiation Medicine, Beijing, China
}

OPEN ACCESS

Edited by:

Lei Zhang,

Third Military Medical University, China

Reviewed by:

Yael Stein,

Hadassah Medical Center, Israe

Sareesh Naduvil Narayanan,

Ras al-Khaimah Medical and Health

Sciences University,

United Arab Emirates

Gui Rong Ding,

Fourth Military Medical

University, China

*Correspondence:

Hongyan Zuo

zuohy2005@126.com

Yang $\mathrm{Li}$

leeyoung109@hotmail.com

Specialty section:

This article was submitted to

Radiation and Health,

a section of the journal

Frontiers in Public Health

Received: 07 April 2021

Accepted: 13 July 2021

Published: 17 August 2021

Citation:

Hu C, Zuo H and Li Y (2021) Effects of

Radiofrequency Electromagnetic Radiation on Neurotransmitters in the Brain. Front. Public Health 9:691880.

doi: 10.3389/fpubh.2021.691880
With the rapid development of electronic information in the past 30 years, technical achievements based on electromagnetism have been widely used in various fields pertaining to human production and life. Consequently, electromagnetic radiation (EMR) has become a substantial new pollution source in modern civilization. The biological effects of EMR have attracted considerable attention worldwide. The possible interaction of EMR with human organs, especially the brain, is currently where the most attention is focused. Many studies have shown that the nervous system is an important target organ system sensitive to EMR. In recent years, an increasing number of studies have focused on the neurobiological effects of EMR, including the metabolism and transport of neurotransmitters. As messengers of synaptic transmission, neurotransmitters play critical roles in cognitive and emotional behavior. Here, the effects of EMR on the metabolism and receptors of neurotransmitters in the brain are summarized.

Keywords: EMR, brain, neurotransmitter, metabolism, transmission, receptor

\section{BACKGROUND}

Electromagnetic radiation (EMR) is closely related to human life and originates from various electrical systems, such as mobile phones, microwave ovens, communication base stations, high-voltage lines, electronic instruments and other electromagnetic equipment. EMR produces various electromagnetic waves of different frequencies, resulting in the increasing EMR intensity in human living spaces. The high-frequency waves such as cosmic, gamma and X-rays, have enough energy to cause ionization. Non-ionizing electromagnetic waves, including ultraviolet, visible region, infrared, microwave, and radio waves are frequently used in daily life, especially radiofrequency electromagnetic fields (RF-EMFs, $30 \mathrm{kHz}-300 \mathrm{GHz}$ ) for communications, and extremely low-frequency EMFs (ELF-EMFs, $3 \mathrm{~Hz}-3 \mathrm{kHz}$ ) generated by electricity. RF is also commonly referred to as microwave (MW) radiation. The impact of EMR on human health has also gradually attracted attention, and the modulation of brain functional connectivity was observed in human body (1-3). This review summarizes the effects of RF-EMF on neurotransmitters in the brain.

The effects of EMR on body systems might depend on the frequency, intensity and power of radiation, so the parameters of EMR provide a challenge for a literature review. Specific absorption rate (SAR) measures the rate of energy absorbed by the human body when exposed to electromagnetic fields between $100 \mathrm{kHz}$ and $10 \mathrm{GHz}$. With the unit of watt per kilogram $(\mathrm{W} / \mathrm{kg})$, SAR reflects the power absorbed per mass of tissue. The SAR value depends on the frequency, incident direction, E-polarization direction, and the structure of different tissues.So far, the SAR values range from $10^{-4}$ to $35 \mathrm{~W} / \mathrm{kg}$ in those reported studies on the bioeffects of microwave radiation. 
Numerous studies have shown that the nervous system is an important target organ system sensitive to EMR. Exposure to electromagnetic fields can cause structural and functional changes in the nervous system (4-7). Neurotransmitters are specific chemicals that act as messengers during synaptic transmission within the nervous system. Many studies have shown that EMR affects the metabolism and transport of neurotransmitters (8). It is well understood that neural circuit is the structural basis of brain function, and the brain works by the interplay of various brain regions and many neurotransmitters. Consequently, the modulatory effect of EMR on neurotransmitter levels in various brain regions may play a critical role in the brain functioning. According to many studies, RF-EMR exposure can induce the imbalance of amino acid neurotransmitters in various parts of the brain $(9,10)$.

Neurotransmitters are synthesized by nerve cells and transported into the synaptic vesicles of presynaptic cells. Through action potentials, transmitter release at synaptic endings is mediated by calcium ion channels; transmitters are then diffused through the synaptic cleft and act on specific receptors on postsynaptic neurons or effector cells, thus transferring information from presynapses to postsynapses (11). The action of neurotransmitters can be discontinued by recycling; that is, excess neurotransmitters in the synaptic cleft are recycled to presynaptic neurons by the action of presynaptic vectors and are stored in vesicles. Neurotransmitter activity can also be aborted by enzymatic hydrolysis; for instance, dopamine (DA), is metabolically inactivated by the actions of monoamine oxidase located in mitochondria and catechol-O-methyltransferase (COMT) located in the cytoplasm (12). Neurotransmitters are involved in the processes of brain development, including neurotransmission, differentiation, and the formation of neural circuitry. They enable neurons to communicate with each other, and alterations in the levels of specific neurotransmitters are related to various neurological disorders, such as depression, schizophrenia, Alzheimer disease, and Parkinson disease (13). Neurotransmitters in the central nervous system are usually divided into four categories based on their chemical constitution. Biogenic amines include DA, norepinephrine (NE), epinephrine (E), 5-hydroxytryptamine (5-HT), etc. Amino acids include $\gamma$-aminobutyric acid (GABA), glycine, glutamate, acetylcholine (Ach), etc. Peptide neurotransmitters include endogenous opioid peptides and other varieties. The remaining category of transmitters includes other types, such as nitric oxide (NO) and substance P. Pertinently, the current review discusses the pivotal studies that shed light on the neurotransmitters in the brain in the above mentioned four categories when they encountered EMR exposure, thus providing an overview of the metabolism and receptor changes of these neurotransmitters.

For the literature retrieval, we searched all the articles in the NCBI PubMed database, with the keywords of each "neurotransmitter" and "electromagnetic field" or "radiofrequency electromagnetic field," and selected the published articles written in English and referring to neurotransmitter measurement in the brain encounter with RF-EMF exposure. Overall, 21 articles related to neurotransmitters with short-term EMR exposure were discussed in the text and summarized in Table 1, and 19 articles related to neurotransmitters with long-term EMR exposure were discussed in the text and summarized in Table 2.

\section{EFFECTS OF EMR ON BIOLOGICAL AMINE NEUROTRANSMITTERS \\ Effects of EMR on Dopamine (DA)}

As a precursor of norepinephrine, DA is a key neurotransmitter in the hypothalamus and pituitary gland. It is mainly responsible for activity in the brain associated with reward, learning, emotion, motor control, and executive functions. DA also correlates to psychiatric and neurological disorders, including Parkinson disease, multiple sclerosis, and Huntington disease (13). It has been suggested that DA inhibits the secretion of gonadotropin-releasing hormone, and there is an axonal connection and interaction between gonadotropin-releasing hormone and DA in nerve endings (49). Deficiency of DA in the basal ganglia is seen in patients with Parkinsonism (50). DA also has some role in Schizophrenia-striatal DA is increased, and cortical DA transmission is altered $(51,52)$.

Several studies reported the effects of EMR on DA. For example, adult rats undergoing daily EMR exposure for $1 \mathrm{~h}$, with an EMR frequency of $1,800 \mathrm{MHz}$, a specific absorption rate (SAR) value of $0.843 \mathrm{~W} / \mathrm{kg}$, power density of $0.02 \mathrm{~mW} / \mathrm{cm}^{2}$, induced a significant decrease in DA in the hippocampus after 2 months of exposure and 1 month after cessation of exposure. This study indicated that EMR exposure may reduce DA production in the hippocampus, affect rat arousal, and contribute to decreased learning and memory ability after exposure to EMR (14). Maaroufi et al. exposed rats to $900 \mathrm{MHz}$ EMF, 1 h/day during 21 consecutive days, with the minimum SAR $0.05 \mathrm{~W} / \mathrm{kg}$ and the maximum SAR $0.18 \mathrm{~W} / \mathrm{kg}$, depending on the position of the rat in the field. A decrease in DA was observed in the hippocampus of the EMR exposed group. Moreover, there is a significant difference of DA and dihydroxyphenyl acetic acid (DOPAC) between hippocampus and striatum in the EMR exposed group (34). Furthermore, exposure to a RF-EMR of $835 \mathrm{MHz}$, SAR value of $4.0 \mathrm{~W} / \mathrm{kg}$, for $5 \mathrm{~h}$ /day for 12 weeks, led to a reduction in DA concentration in the striatum of C57BL/6 mice (33). The above studies suggest that a certain intensity of microwave radiation can lead to abnormal metabolism of monoamine neurotransmitters in the hippocampus and striatum.

Inaba et al. exposed adult rats to microwave radiation for $1 \mathrm{~h}$, with the frequency of 2,450 MHz, and at power densities of 5 and $10 \mathrm{~mW} / \mathrm{cm}^{2}$ respectively. The DOPAC content in the pons and medulla oblongata, the DA turnover rates and the DOPAC:DA ratio increased significantly in the striatum and cerebral cortex only at a power density of $10 \mathrm{~mW} / \mathrm{cm}^{2}$, but no significance was observed in the DA content of any region of the brain at a power density of $5 \mathrm{~mW} / \mathrm{cm}^{2}$ (15). In addition, 32 pregnant Wistar rats were divided into control group, low-dose group (receiving mobile phone radiation for 10 -min periods), middle-dose group (receiving mobile phone radiation for 30-min periods), and high-dose group (receiving mobile phone radiation for 60 -min periods). Rats underwent 
TABLE 1 | The influence of short-term EMR exposure on neurotransmitters in the brain.

\begin{tabular}{|c|c|c|c|}
\hline Neurotransmitter & Reference & Sample/Model & Exposure condition \\
\hline \multirow[t]{2}{*}{ DA } & $\begin{array}{l}\text { Aboul Ezz et al. } \\
\text { (14) }\end{array}$ & Adult rats & $\begin{array}{l}1800 \mathrm{MHz}, 0.843 \mathrm{~W} / \mathrm{kg}, 0.02 \\
\mathrm{~mW} / \mathrm{cm}^{2}, 1 \mathrm{~h}\end{array}$ \\
\hline & Inaba et al. (15) & Rats & $2450 \mathrm{MHz}, 5$ and $10 \mathrm{~mW} / \mathrm{cm}^{2}, 1 \mathrm{~h}$ \\
\hline \multirow[t]{2}{*}{$5-\mathrm{HT}$} & Inaba et al. (15) & Rats & $2450 \mathrm{MHz}, 5$ and $10 \mathrm{~mW} / \mathrm{cm}^{2}, 1 \mathrm{~h}$ \\
\hline & Ishikawa et al. (16) & Male Wistar rats & $2450 \mathrm{MHz}, 5 \mathrm{~kW} ; 0.5$ or $1.5 \mathrm{~s}$ \\
\hline \multirow{4}{*}{$\begin{array}{l}\text { Glutamate } \\
\& \text { aspartic } \\
\text { acid }\end{array}$} & Karri et al. (17) & Wistar rats & $30 \mathrm{~mW} / \mathrm{cm}^{2}, 10 \mathrm{~min}$ \\
\hline & Wei et al. (1) & Male Wistar rats & $5,10,30$, and $100 \mathrm{~mW} / \mathrm{cm}^{2} ; 5 \mathrm{~min}$ \\
\hline & $\begin{array}{l}\text { Mausset- } \\
\text { Bonnefont et al. } \\
\text { (18) }\end{array}$ & Rats & $900 \mathrm{MHz}, 6 \mathrm{~W} / \mathrm{kg}, 15 \mathrm{~min}$ \\
\hline & Zhang et al. (19) & Rats & $12.0 \mathrm{~W} / \mathrm{kg}, 65 \mathrm{~mW} / \mathrm{cm}^{2}, 20 \mathrm{~min}$ \\
\hline
\end{tabular}

\begin{tabular}{|c|c|c|c|}
\hline & Wang et al. (20) & Rats & $65 \mathrm{~mW} / \mathrm{cm}^{2}, 12.0 \mathrm{~W} / \mathrm{kg}, 20 \mathrm{~min}$ \\
\hline & Xiong et al. (21) & Male Wistar rats & $\begin{array}{l}2.856 \mathrm{GHz}, 30 \mathrm{~mW} / \mathrm{cm}^{2} \text {, for } 10 \mathrm{~min} \\
\text { every other day three times }\end{array}$ \\
\hline \multirow[t]{4}{*}{ GABA } & Qiao et al. (22) & Wistar rats & $30 \mathrm{~mW} / \mathrm{cm}^{2}, 5 \mathrm{~min}$ \\
\hline & Wang et al. (23) & Wistar rats & $2.856 \mathrm{GHz}, 50 \mathrm{~mW} / \mathrm{cm}^{2}, 6 \mathrm{~min}$ \\
\hline & Noor et al. (9) & Male albino rats & $\begin{array}{l}900 \mathrm{MHz}, 1.165 \mathrm{~W} / \mathrm{kg}, 0.02 \\
\mathrm{~mW} / \mathrm{cm}^{2}, 1 \mathrm{~h} / \text { day }\end{array}$ \\
\hline & Wang et al. (24) & Rats & $900 \mathrm{MHz}, 2.23 \mathrm{~W} / \mathrm{kg}, 6 \mathrm{~mW} / \mathrm{cm}^{2}$ \\
\hline \multirow[t]{5}{*}{ ACh } & Fujiwara et al. (25) & Mice & $2.45 \mathrm{GHz}$ \\
\hline & Lai et al. (26) & Rats & $2.45 \mathrm{GHz}, 0.6 \mathrm{~W} / \mathrm{kg}, 20 \mathrm{~min}$ \\
\hline & Krylova et al. (27) & Rats & $2.35 \mathrm{GHz}, 1 \mathrm{~mW} / \mathrm{cm}^{2}$ \\
\hline & Testylier et al. (28) & Rats & $2.45 \mathrm{GHz}, 4 \mathrm{~mW} / \mathrm{cm}^{2}, 1 \mathrm{~h}$ \\
\hline & Lai et al. (29) & Rats & $\begin{array}{l}\text { Pulsed ( } 2 \mu \mathrm{s}, 500 \text { pps) or continuous } \\
\text { wave } 2450 \mathrm{MHz} \text { microwaves, } 45 \mathrm{~min}\end{array}$ \\
\hline \multirow[t]{2}{*}{ Peptides } & Lai et al. (30) & Rats & $\begin{array}{l}2450 \mathrm{MHz}, 0.6 \mathrm{~W} / \mathrm{kg}, 1 \mathrm{~mW} / \mathrm{cm}^{2} \text {, } \\
45 \mathrm{~min}\end{array}$ \\
\hline & Lai et al. (31) & Rats & $\begin{array}{l}2450 \mathrm{MHz}, 0.6 \mathrm{~W} / \mathrm{kg}, 1 \mathrm{~mW} / \mathrm{cm}^{2} \text {, } \\
45 \mathrm{~min}\end{array}$ \\
\hline NO & Burlaka et al. (32) & Wistar rats & $\begin{array}{l}0.465 \mathrm{GHz}, 1.0-6.0 \mathrm{~mW} / \mathrm{cm}^{2} \text { pulse } \\
\text { duration } 2 \mathrm{~ms}, 17.5 \mathrm{~min}\end{array}$ \\
\hline
\end{tabular}


TABLE 2 | The influence of long-term EMR exposure on neurotransmitters in the brain.

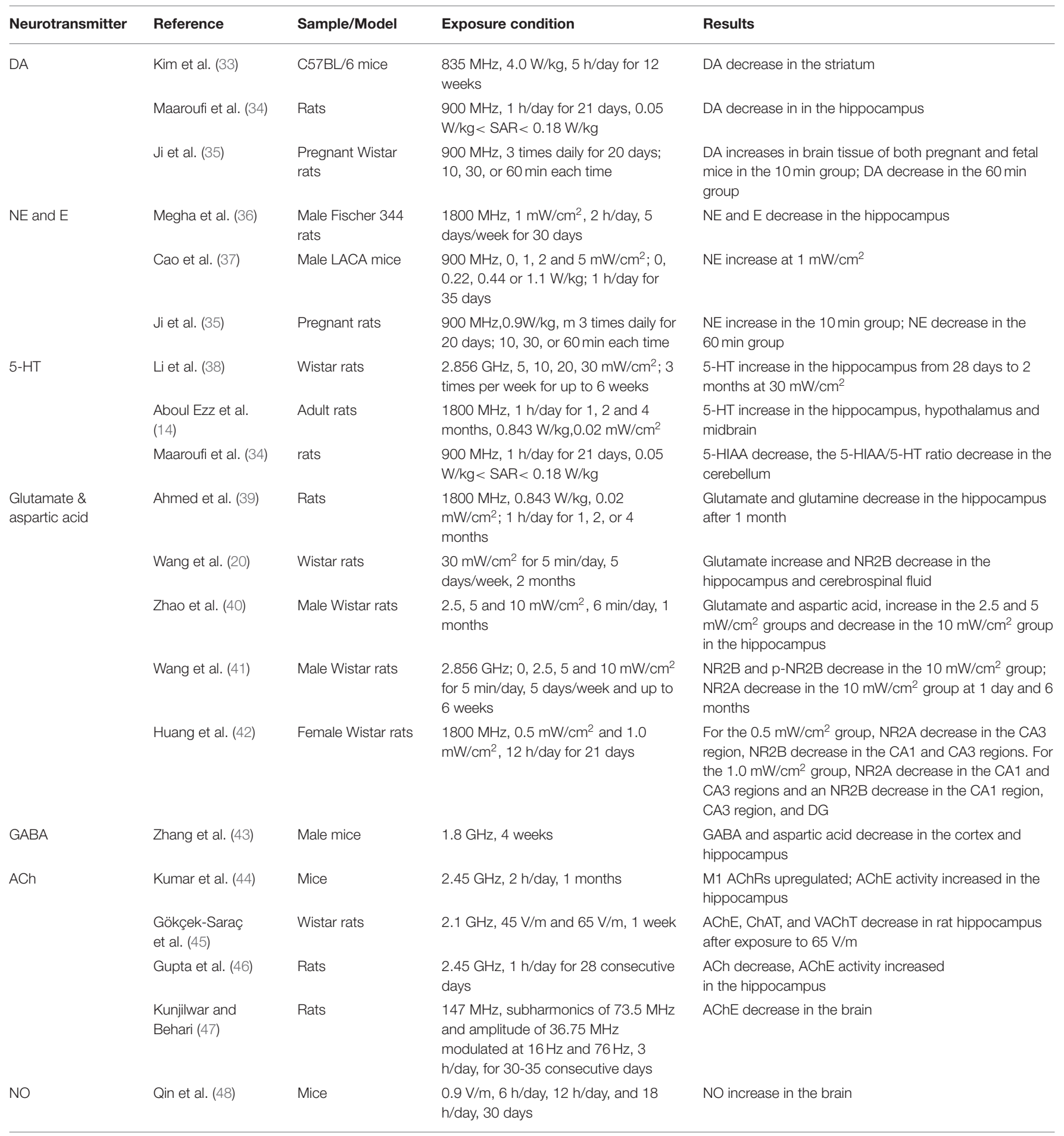

in the low-dose group but decreased in the high-dose group, and no significant changes were observed in the middledose group, which suggested that long-term mobile phone radiation could cause abnormal DA content in the central nervous system in fetal mice and might affect the brain development of mice (35). In summary, these studies indicate that EMR can lead to metabolic disorders of monoamine neurotransmitters in the brain, depending on the intensity of radiation exposure, and might in theory result in abnormal emotional behavior. 


\section{Effects of EMR on Norepinephrine and Epinephrine}

As a neurotransmitter, norepinephrine is mainly synthesized and secreted by sympathetic postganglionic neurons and adrenergic nerve endings in the brain. A small number of norepinephrine is produced in adrenal medulla as a hormone (53). It can bind to two types of adrenergic receptors, $\alpha$ and $\beta$, but it mainly binds to $\alpha$ receptors (including $\alpha 1$ and $\alpha 2$ ). Norepinephrine can be converted to epinephrine through N-methylation (54). The release of norepinephrine in the brain plays a role in various processes, such as stress, attention, sleep, inflammation, and the responses of the autonomic nervous system (13). Megha et al. found that after 30 days ( $2 \mathrm{~h} /$ day, 5 days/week) of continuous $1,800 \mathrm{MHz}, 1 \mathrm{~mW} / \mathrm{cm}^{2}$ microwave radiation, the levels of norepinephrine and epinephrine in rat hippocampal tissue were significantly decreased, indicating that certain conditions of microwave radiation could lead to a decrease in norepinephrine and epinephrine contents in the brain (36). Cao et al. applied $900 \mathrm{MHz}$ microwave radiation to male LACA mice. The radiation intensity used was $0,1,2$, and 5 $\mathrm{mW} / \mathrm{cm}^{2}$; the SAR values were $0,0.22,0.44$, and $1.1 \mathrm{~W} / \mathrm{kg}$, respectively; mice were exposed for $1 \mathrm{~h}$ /day for 35 consecutive days. The results showed that the brain norepinephrine content increased significantly when EMR intensity was $1 \mathrm{~mW} / \mathrm{cm}^{2}$, but no obvious changes in norepinephrine content were observed when exposure intensity was 2 or $5 \mathrm{~mW} / \mathrm{cm}^{2}$ (37). This further suggests that low-intensity EMR exposure can cause an increase in norepinephrine content in the brain, which might in theory affect epinephrine content, leading to neurotransmitter production disorders.

Moreover, Ji et al. performed experiments on pregnant rats by exposing them to microwave radiation from $900 \mathrm{MHz}$ cellular phones with the SAR value of $0.9 \mathrm{~W} / \mathrm{kg}$. The control, low, middle and high dose group received $0,10,30$, and $60 \mathrm{~min}$ radiation each time respectively. The radiation was applied three times a day from the first day of pregnancy for 20 consecutive days. The results showed that the norepinephrine content in the fetal rats of the low dose group increased, and the norepinephrine content in the fetal rats of the high dose group decreased significantly, compared with that in the control group (35). Together, these results suggest that long-term exposure to EMR may lead to abnormal norepinephrine and epinephrine contents in the brain, depending on the dose of radiation.

\section{Effects of EMR on 5-Hydroxytryptamine "Serotonin"}

5-hydroxytryptamine (5-HT) is massively synthesized in the gastrointestinal tract (mainly in enterochromafin cells), whereas only a small percentage is produced within the nervous system. In the brain, 5-HT cell bodies, mainly localized in the raphe nuclei, and send axons to almost every brain region (55). As an inhibitory neurotransmitter, 5-HT is mainly distributed in the pineal gland and hypothalamus, especially in the cerebral cortex and neural synapses. 5-HT contributes to the regulation of physiological functions such as mood, feeding, cognition, memory, pain, sleep, and body temperature maintenance
(56), and these physiological functions have been reported as indicators of brain injury induced by electromagnetic radiation (57). Consequently, 5-HT might play an important role in the neurobiological effects of EMR. Few studies have reported the effect of microwave radiation on 5-HT. It was reported that rats were exposed to microwave radiation for $1 \mathrm{~h}$, with a frequency of 2,450 MHz, at power densities of 5 and $10 \mathrm{~mW} / \mathrm{cm}^{2}$. The 5-hydroxyindoleacetic acid (5-HIAA) content in the cerebral cortex was significantly increased after microwave exposure at power densities of 5 and $10 \mathrm{~mW} / \mathrm{cm}^{2}$. The $5-\mathrm{HT}$ turnover rates and the 5-HIAA:5-HT ratio in the cerebral cortex increased significantly at a power density of $5 \mathrm{~mW} / \mathrm{cm}^{2}$. However, there were no obvious changes in 5 - $\mathrm{HT}$ content in the brain of microwave-exposed rats. Consistently, the 5-HT turnover rate was significantly increased in the pons, medulla oblongata and hypothalamus at a power density of $10 \mathrm{~mW} / \mathrm{cm}^{2}(15)$.

$\mathrm{Li}$ et al. exposed Wistar rats to $2.856 \mathrm{GHz}$ microwave radiation, with mean power densities of $5,10,20$, and 30 $\mathrm{mW} / \mathrm{cm}^{2}$, separately, three times per week for up to 6 weeks. Spatial learning and memory function, the hippocampal morphological structure, electroencephalogram (EEG) data and neurotransmitter content of rats were tested after the last exposure. The results showed that the content of 5-HT in the hippocampus and cerebrospinal fluid of rats in each radiation group increased significantly from 28 days to 2 months after exposure, and these changes were related to the decrease in learning and memory ability, abnormal hippocampal morphology and abnormal EEG results induced by microwave radiation (38). Maaroufi et al. reported the 5-HT increase, the 5-HIAA decrease and the 5-HIAA/5-HT ratio decrease in the cerebellum of rats, exposed to $900 \mathrm{MHz}$ EMF, $1 \mathrm{~h} /$ day for 21 consecutive days, with the minimum SAR $0.05 \mathrm{~W} / \mathrm{kg}$ and the maximum SAR $0.18 \mathrm{~W} / \mathrm{kg}$ (34). Moreover, the 5-HT increase was found in the hippocampus, hypothalamus and midbrain of adult rats, after $1,800 \mathrm{MHz}$, $1 \mathrm{~h} /$ day for 1,2 , and 4 months EMR exposure respectively, with SAR value of $0.843 \mathrm{~W} / \mathrm{kg}$, and power density of 0.02 $\mathrm{mW} / \mathrm{cm}^{2}$ (14). These studies suggest that long-term exposure to microwave radiation can lead to an increase in 5-HT in the brain, indicating a disorder in the metabolism of the neurotransmitter.

Additionally, the effect of microwave radiation on monoamine metabolism was investigated in the cortex, striatum and hippocampus of the rat brain, with the maximum power level of $5 \mathrm{~kW}$ at $2,450 \mathrm{MHz}$, and the radiation durations of 0.5 and $1.5 \mathrm{~s}$. High-performance liquid chromatography (HPLC) with electrochemical detection was used to determine the concentrations of intracerebral monoamines and their metabolites. The concentrations of norepinephrine, DA and 5HIAA were reduced by $0.5 \mathrm{~s}$ radiation. While the levels of these monoamines were increased by $1.5 \mathrm{~s}$ radiation (16). Whereas, another study on pregnant rats exposing to $900 \mathrm{MHz}$ cellular phones, showed no significant difference in the content of 5-HT of fetal rats, in different intensities of microwave radiation groups (35). Altogether, further studies are necessary to illuminate the role of 5-HT in EMR-induced learning and memory dysfunction and morphological changes in the brain. 


\section{EFFECTS OF EMR ON AMINO ACID NEUROTRANSMITTERS \\ Effects of EMR on Excitatory Amino Acid Neurotransmitters}

Glutamate is the major excitatory neurotransmitter in the nervous system. Glutamate receptors distribute in neurons and glia of the brain and spinal cord. The C-terminus and carbon backbone of glutamate derive from glucose. After crossing the blood-brain barrier through astrocytic end feet, glucose is broken down to pyruvic acid via glycolysis in the cytosol. Then pyruvic acid enters the tricarboxylic acid (TCA) cycle, and $\alpha$-ketoglutarate is generated. Pyruvic acid is finally transmitted to receive an amino group donated by leucine, isoleucine and valine, aspartate, $\gamma$-aminobutyric acid (GABA) and alanine etc. (58). In addition, glutamate also acts as a metabolic precursor to GABA and a component of various amino acid-based derivatives, such as the antioxidant glutathione. Metabolic studies have shown that all of the glucose is eventually converted to glutamate in the CNS, which indicating the key role of glutamate in multiple aspects of brain physiology $(59,60)$.

In addition to glutamate, aspartate is another excitatory neurotransmitter with high concentrations in the CNS. The synthetic and metabolic enzymes for both glutamate and aspartate are localized to neurons and glial cells, especially in the mitochondria of neurons involved in the TCA cycle of glucose metabolism. Using oxaloacetic acid as raw materials, catalyzed by aminotransferase, aspartate is synthesized and stored in axon terminals. When nerve impulses are transmitted to axonal terminals, glutamate and aspartate are released by the presynaptic membrane and rapidly diffuse into the postsynaptic membrane; here, they bind to their corresponding receptors and prompt the opening of sodium and potassium channel gates to produce excitatory effects. The presynaptic membrane and glial cells reuptake a small amount of glutamate and aspartate.

Wistar rats were exposed to $30 \mathrm{~mW} / \mathrm{cm}^{2}$ for $10 \mathrm{~min}$ of microwave radiation, and HPLC was used to detect changes in the levels of neurotransmitters, such as aspartate and glutamate, in the hippocampus $1,7,14$, and 28 days after radiation. The results showed that the contents of aspartate and glutamate decreased 1 day after radiation, suggesting that acute EMR exposure could reduce the amount of excitatory amino acids in the hippocampus (17). Consistently, Ahmed et al. investigated the effect of EMR on the concentrations of amino acid neurotransmitters in the hippocampus, striatum, and hypothalamus of juvenile and young adult rats. The animals were divided into the control group and the exposure group, and the exposure group was subjected to $1,800 \mathrm{MHz}$ EMR, with SAR value of 0.843 $\mathrm{W} / \mathrm{kg}$, power density of $0.02 \mathrm{~mW} / \mathrm{cm}^{2}, 1 \mathrm{~h}$ daily for 1,2 , and 4 months. The results showed EMR induced significant decreases in glutamate and glutamine levels in hippocampal after 1 month (39). These data suggest that EMR can lead to a decrease in excitatory amino acid neurotransmitters in the hippocampus, which may affect the excitatory-inhibitory balance of neurons, thus causing a decline in learning and memory ability.
On the other hand, some studies have reported an increase in glutamate in the brain after radiation. Wang et al. exposed 160 Wistar rats to microwave radiation at $30 \mathrm{~mW} / \mathrm{cm}^{2}$ for 5 $\mathrm{min} /$ day, 5 days/week, over a period of 2 months. The learning and memory ability, amino acid contents in the hippocampus and cerebrospinal fluid, and $\mathrm{N}$-methyl $\mathrm{D}$-aspartate receptor (NMDAR) subtype 2B (NR2B) expression were then investigated. Following microwave exposure, rats exhibited a significant decrease in learning and memory ability at 7 days and the glutamate contents in their hippocampus and cerebrospinal fluid increased, whereas the expression of NR2B protein decreased (20). Zhao et al. performed microwave exposure on 184 male Wistar rats for $6 \mathrm{~min} /$ day, over one month, at average power densities of $2.5,5$, and $10 \mathrm{~mW} / \mathrm{cm}^{2}$. Morris water maze was applied to examine the learning and memory abilities. The concentrations of neurotransmitter in the hippocampus was detected by HPLC. The learning and memory ability of rats showed a significant decrease at 7,14, and 1 month, following all three long-term microwave exposures. The concentrations of glutamate, aspartic acid, glycine, and GABA in the hippocampus were all increased for both 2.5 and $5 \mathrm{~mW} / \mathrm{cm}^{2}$ groups, but these four amino acids were decreased in the $10 \mathrm{~mW} / \mathrm{cm}^{2}$ group (40). These data further suggest the neurotransmitter disruption in the hippocampus might result in impairment of cognitive function caused by long-term microwave exposure.

Glutamate receptors are mainly constitutive of two types. The first type comprises ionic receptors, including NMDAR, kainate receptors (KARs) and $\alpha$-amino-3-hydroxy-5-methyl-4isoxazole receptors (AMPARs), which are conjugated with ion channels to form receptor channel complexes and mediate fast signal transmission. The second type encompasses metabolic receptors (mGluRs), which are conjugated to $G$ proteins in the membrane. After being activated, these receptors act through a signal transduction system composed of a G-protein effector enzyme and a second messenger in the brain and produce a slow physiological response. Each NMDAR contains two binding recognition sites for glutamate and glycine, both of which are specific activators of the receptor (61). NMDARs are most often composed of two NR1 subunits and two NR2 subunits, and are highly permeable to $\mathrm{Ca}^{2+}$. NR1 is the basic subunit of NMDAR. For NR2 subunit, there are four subtypes including NR2A, NR2B, NR2C and NR2D. Glutamate binds to the NR2 subunits, while glycine binds to the NR1 subunit. The function of NMDARs is mainly dependent on the N-terminal domain of NR2 subunits $(61,62)$. Some studies have investigated the influence of EMRs on NMDAR expression in the brain.

Wang et al. exposed 220 male Wistar rats to microwave radiation, with frequency of $2.856 \mathrm{GHz}$, for $5 \mathrm{~min} /$ day, 5 days/week, over 6 weeks, at average power densities of $0,2.5,5$, and $10 \mathrm{~mW} / \mathrm{cm}^{2}$ respectively. For the $10 \mathrm{~mW} / \mathrm{cm}^{2}$ group, the escape latency of rats significantly prolonged in the navigation tests of the Morris water maze, at 7 days, 1, 3, and 9 months after radiation. At 3 days after radiation, a significant impairment of rats in the probe trials was found in the $10 \mathrm{~mW} / \mathrm{cm}^{2}$ group. Additionally, the protein levels of NR2A, NR2B and p-NR2B significantly decreased, and no significant change was observed for NR1 expression in the $10 \mathrm{~mW} / \mathrm{cm}^{2}$ group from 1 day to 12 
months after radiation. This suggests that decreases in NR2A, $2 \mathrm{~B}$ and $\mathrm{p}-\mathrm{NR} 2 \mathrm{~B}$ might contribute to the impairment of cognitive functions induced by microwave radiation (41).

Mausset et al. using a head-only exposure device in rats, found that a $15 \mathrm{~min}$ exposure to $900 \mathrm{MHz}$ pulsed microwaves at a SAR value of $6 \mathrm{~W} / \mathrm{kg}$ induced a strong glial reaction in the brain, a significant reduction in NR1 subunits in the cortex, a reduction in NR2A in the cortex and hippocampus, and a reduction in NR2B in the striatum. This suggests that exposure to high-power $900 \mathrm{MHz}$ pulsed microwave radiation promotes specific NMDAR degradation processes (18). Moreover, Huang et al. exposed four-week-old female Wistar rats to $1800 \mathrm{MHz}$ microwaves, at power densities of $0.5 \mathrm{~mW} / \mathrm{cm}^{2}$ or $1.0 \mathrm{~mW} / \mathrm{cm}^{2}$, for 21 days and $12 \mathrm{~h}$ each day. The expression of NR2A and NR2B in the hippocampal CA1, CA3 and dentate gyrus (DG) was determined by immunohistochemistry. For NR2A, the expression in the $0.5 \mathrm{~mW} / \mathrm{cm}^{2}$ group was significantly lower than that in the 0 $\mathrm{mW} / \mathrm{cm}^{2}$ group in CA3, but no significant changes were noted in CA1 and the DG. The expression in the $1.0 \mathrm{~mW} / \mathrm{cm}^{2}$ group was significantly lower in CA1 and CA3, but no significant changes were found in the DG. For NR2B, the expression in the $0.5 \mathrm{~mW} / \mathrm{cm}^{2}$ group was significantly lower than that in the $0 \mathrm{~mW} / \mathrm{cm}^{2}$ group in CA1 and CA3. The expression in the 1.0 $\mathrm{mW} / \mathrm{cm}^{2}$ group was significantly lower in CA1, CA3 and the DG (42). This further suggests that the decrease of NR2A and NR2B induced by microwave exposure depends on the dose of radiation and the district of hippocampus.

In addition, after microwave radiation exposure of 65 $\mathrm{mW} / \mathrm{cm}^{2}$ for $20 \mathrm{~min}$ (SAR value $12.0 \mathrm{~W} / \mathrm{kg}$ ), the mRNA expression of the NR1 subunit in the hippocampus decreased at 3, 24h, and 3 days, and the expression of the NR2A subunit decreased at $0 \mathrm{~h}, 3 \mathrm{~h}$, and $12 \mathrm{~h}$ after microwave exposure. The mRNA expression of the NR2C subunit decreased at 0 and $24 \mathrm{~h}$, but the expression of the NR2D subunit increased at 0 , $12,24 \mathrm{~h}$, and 3 days after radiation. No significant changes in NR2B mRNA expression were observed (19). However, Xiong et al. exposed 48 male Wistar rats to $2.856 \mathrm{GHz}, 30 \mathrm{~mW} / \mathrm{cm}^{2}$ microwave radiation, for $10 \mathrm{~min}$ every other day three times. The mRNA expression of the NR2A subunit notably increased at 7 days, and the mRNA expression of the NR2B subunit in the rat hippocampus increased at 1 day after microwave exposure (21). Together, these results indicate that the composition of subunits comprising NMDARs can be altered and that the autoregulation of NMDARs can be destroyed in the rat hippocampus after exposure to microwave radiation. Furthermore, microwave radiation may affect the expression of excitatory amino acids.

\section{Effects of EMR on Inhibitory Amino Acid Neurotransmitters}

GABA and glycine are the main inhibitory neurotransmitters in the brain, and GABA is an important neurotransmitter for approximately $50 \%$ of the synaptic sites in the central nervous system. GABA plays a critical role in the cerebral cortex, hippocampus, thalamus, basal ganglia and cerebellum, and has a regulatory role in various functions of the body, such as the regulation of emotion, memory and sleep, antihypertension, antifatigue, analgesia, etc. (63). GABA is produced in nerve endings catalyzed by glutamate decarboxylase. After release from the presynaptic membrane, most GABA diffuses to the postsynaptic membrane, causing an inhibitory effect in the postsynaptic membrane. The presynaptic membrane and glial cells reuptake a few GABA molecules, which are converted into succinic semi formaldehyde in mitochondria and then converted into succinic acid, which participates in the tricarboxylic acid cycle and provides a small part of the energy for glial cells and neural terminals $(64,65)$. Qiao et al. exposed Wistar rats to microwave radiation, with an average power density of $30 \mathrm{~mW} / \mathrm{cm}^{2}$ for $5 \mathrm{~min}$; then, HPLC was used to determine the GABA content released by hippocampal synaptosomes $6 \mathrm{~h}$ after exposure. The results showed that the amount of GABA released by hippocampal synaptosomes significantly decreased after radiation exposure (22). Zhang et al. investigated the effects of EMR exposure on the emotional behavior and spatial memory of adolescent male mice, with frequency of $1.8 \mathrm{GHz}$, and time duration of 4 weeks. The authors found that the levels of GABA and aspartic acid in the cortex and hippocampus significantly decreased after EMR exposure (66). These results suggest that EMR can reduce GABA neurotransmission.

Wang et al. exposed 80 Wistar rats to a $2.856 \mathrm{GHz}$ pulsed microwave radiation, at a power density of $50 \mathrm{~mW} / \mathrm{cm}^{2}$ for $6 \mathrm{~min}$. The contents of amino acid neurotransmitters in the hippocampus were detected at 1, 3, 6, 9, 12, and 18 months after microwave exposure. The results showed that the glutamate to GABA ratio significantly decreased at 6 months after exposure (23). Noor et al. investigated the effect of $1 \mathrm{~h}$ of daily exposure to EMR, with a frequency of $900 \mathrm{Mz}$, SAR value $1.165 \mathrm{~W} / \mathrm{kg}$, power density $0.02 \mathrm{~mW} / \mathrm{cm}^{2}$, on the levels of amino acid neurotransmitters in the midbrain, cerebellum, and medulla of adult male albino rats. The assessment of amino acid levels was applied after $1 \mathrm{~h}, 1,2$, and 4 months of radiation exposure. A significant glycine increase in the midbrain was observed after 1 month, followed by a significant increase in GABA after 4 months (9). These results further suggest that microwave radiation may affect the neuroregulatory function of GABA, resulting in an imbalance in excitation and inhibition in the central nervous system.

In the central nervous system, GABA acts as an inhibitory transmitter. GABA receptors include ligand-gated GABA (A) channels and G-protein-coupled GABA (B) receptors, which mediate inhibitory postsynaptic transmission throughout the nervous system (67). In one study, primary cultured rat cortical neurons were exposed to $900 \mathrm{MHz}$ microwave radiation, with an average power density of $6 \mathrm{~mW} / \mathrm{cm}^{2}$ and SAR value of $2.23 \mathrm{~W} / \mathrm{kg}$. As a result, the expression of neuronal GABA receptor proteins was significantly upregulated (24). Few studies have reported the effects of EMR on GABA receptors. Further investigation to clarify the role of GABA and its receptors during EMR exposure is necessary in the future. Overall, the above studies suggest that EMR can cause metabolic disorders of the inhibitory neurotransmitters GABA and glycine, which may lead to neuronal dysfunction by affecting the neuronal excitationinhibition balance. 


\section{Effects of EMR on Acetylcholine (Ach)}

Cholinergic fiber projection from the basal forebrain to the cortex and hippocampus is the most important cholinergic system in the brain, and the cholinergic system plays a critical role in behavioral cognition. Ach is released from cholinergic nerve endings, and it was the first neurotransmitter to be measured in the brain. Changes in Ach in the extracellular fluid of the brain are closely related to functional changes in the central nervous system. Ach is synthesized by choline and acetyl-CoA under the catalysis of choline acetyltransferase (ChAT) and then taken up and stored by vesicles. When the neuronal presynaptic membrane is excited, Ach in synaptic vesicles is released into the synaptic cleft and acts on G-protein-coupled muscarinic acetylcholine receptors (mAChRs) or ligand-gated nicotinic acetylcholine receptors (nAChRs). Synaptic transmission efficacy can be changed by receptor-mediated membrane depolarization and downstream signal transduction, thus affecting learning and memory. Postacting Ach is hydrolyzed to choline and acetic acid by acetylcholine esterase (AChE) and inactivated (68). The mode of action of Ach in learning and memory depends on the type of receptor it activates (69).

Few studies have been reported on the metabolism of Ach in brains exposed to EMR. Fujiwara et al. found that $2.45 \mathrm{GHz}$ high-power microwave radiation caused transiently elevated Ach content in the mouse brain (25). Lai et al. found that acute exposure to $2.45 \mathrm{GHz}, 0.6 \mathrm{~W} / \mathrm{kg}$ microwave radiation for 20 min caused increased choline uptake activity in the frontal cortex, hippocampus, and hypothalamus of rats (26). Meanwhile, $2.45 \mathrm{GHz}, 0.6 \mathrm{~W} / \mathrm{kg}$ microwave radiation for $20 \mathrm{~min} /$ day for 10 consecutive days resulted in a decrease in the $\mathrm{mAChR}$ concentration in the rat frontal cortex and hippocampus, whereas radiation exposure of $45 \mathrm{~min} /$ day for 10 consecutive days resulted in an increase in the $\mathrm{mAChR}$ concentration in the rat hippocampus, both coinciding with a decrease in learning and memory ability. In addition, Krylova et al. found that $2.35 \mathrm{GHz}, 1 \mathrm{~mW} / \mathrm{cm}^{2}$ microwave radiation could induce a decrease in the functional activity of mAChRs in the rat cerebral cortex, though the number of $\mathrm{mAChR}$ receptors increase (27). We found an increase in Ach, ChAT and AChE in the rat hippocampus at $6 \mathrm{~h}$ and 3 days after microwave radiation, with a frequency of $2.856 \mathrm{GHz}$, and an average power density of $30 \mathrm{~mW} / \mathrm{cm}^{2}$ for $15 \mathrm{~min}$ but no significant effect on the activity of ChAT and AChE. Moreover, we found that the expression of M1-, M3- and $\beta 2$-type AChR mRNA was downregulated, whereas the expression of $\alpha 4$ - and $\alpha 7$-type AChR mRNA was upregulated after radiation exposure. This indicates that the increased synthesis and metabolism of Ach and the disordered expression of Ach receptors may result in cholinergic system dysfunction and a decrease in cognitive function in the early period of acute microwave radiation exposure.

Furthermore, Testylier et al. found that the Ach released in the hippocampal CA1 area decreased after $1 \mathrm{~h}$ of microwave radiation exposure with $2.45 \mathrm{GHz}$ and $4 \mathrm{~mW} / \mathrm{cm}^{2}$, and the extracellular Ach concentration reached the lowest level of approximately $60 \%$ pre-exposure at $6 \mathrm{~h}$ after radiation (28). Other studies have shown that the M1 type of AChR is upregulated, the activity of AChE is increased, and the intracellular calcium concentration is increased in the hippocampus after long-term and low-dose microwave radiation at $2.45 \mathrm{GHz}(44,70)$. Derin et al. arranged Wistar rats into a sham-exposed group and 45 and $65 \mathrm{~V} / \mathrm{m}$ exposed groups; the exposure group experienced 1 week of exposure at a frequency of $2.1 \mathrm{GHz}$. The protein and mRNA expression levels of AChE, ChAT, and VAChT in the hippocampus were examined using western blot and real-time PCR. The levels of AChE, ChAT, and VAChT were significantly lower in the rat hippocampus exposed to $65 \mathrm{~V} / \mathrm{m}$ than in other regions (45). Additionally, sodium-dependent high-affinity choline uptake was measured in the striatum, frontal cortex, hippocampus, and hypothalamus of rats, after $45 \mathrm{~min}$ of shortterm exposure to pulsed ( $2 \mu \mathrm{s}, 500$ pulses per second) or continuous 2,450 $\mathrm{MHz}$ microwaves in cylindrical waveguides. The average whole-body SAR value was $0.6 \mathrm{~W} / \mathrm{kg}$ in all exposure conditions. The choline uptake was decreased in the frontal cortex after microwave exposure in all the radiation conditions (29). Gupta et al. reported a decrease in Ach content and an increase in AChE activity in the rat hippocampus caused by microwave radiation with $2.45 \mathrm{GHz}, 1 \mathrm{~h} /$ day, for 28 consecutive days (46). Kunjilwar and Behari examined the effect of long-term exposure to RF-EMF on cholinergic systems in the developing rat brain, with a frequency of $147 \mathrm{MHz}$, subharmonics of 73.5 $\mathrm{MHz}$ and an amplitude of $36.75 \mathrm{MHz}$ modulated at 16 and $76 \mathrm{~Hz}$, $3 \mathrm{~h} /$ day, for 30-35 consecutive days. A significant decrease in AChE activity was found in exposed rats compared to control rats (71). These studies further suggested that disorders of Ach synthesis and metabolism are an important part of the cognitive dysfunction caused by EMR.

\section{EFFECTS OF EMR ON PEPTIDES AND OTHER NEUROTRANSMITTERS}

Opioid peptides include $\beta$-endorphins, enkephalins and dynorphins, which are peptides with morphine-like activity in the brain. The Opioid receptors are G-protein-coupled receptors. Endogenous opioid receptors are able to inhibit adenosine cyclase, reduce voltage-dependent calcium channel currents or activate potassium channels, resulting in a decrease in membrane excitability and transmitter release, thus participating in the regulation of learning and memory processes (72). Lai et al. investigated subtypes of opioid receptors in the brain exposed to a $45 \mathrm{~min}$ of short-term exposure to pulsed microwaves $(2,450$ $\mathrm{MHz}, 1 \mathrm{~mW} / \mathrm{cm}^{2}$, SAR value $0.6 \mathrm{~W} / \mathrm{kg}$ ) on cholinergic activity in the rat brain. The results showed that 3 opioid receptor subtypes blocked the decrease in cholinergic activity in the hippocampus induced by microwave radiation, suggesting that the opioid system is involved in microwave-induced hippocampal cholinergic activity decrease (30). There are few reports on the effect of EMR on peptide neurotransmitters. Lai et al. reported that after $45 \mathrm{~min}$ of exposure to pulsed $2,450 \mathrm{MHz}$ microwaves $\left(1 \mathrm{~mW} / \mathrm{cm}^{2}\right.$, SAR value $\left.0.6 \mathrm{~W} / \mathrm{kg}\right)$, rats showed learning impairment while performing in the radial arm maze to obtain food rewards. This indicated a deficit in spatial working memory function after EMR exposure. The 
microwave-induced learning deficit in the radial arm maze was blocked by pretreatment with the opiate antagonist naltrexone or a cholinergic agonist. This further suggests that both endogenous opioid neurotransmitter and cholinergic systems in the brain are involved in microwave-induced spatial memory deficits (31).

Nitric Oxide (NO) acts as a retrograde messenger in synaptic plasticity changes and long-term potentiation effects (48). Mice were exposed to computer electromagnetic radiation $\left(30 \times 10^{14}\right.$ $715 \times 10^{14} \mathrm{~Hz}$ ) with an intensity of $0.9 \mathrm{~V} / \mathrm{m}$ (power density 0.22 $\mu \mathrm{w} / \mathrm{cm}^{2}$ ) for either 6,12 , and $18 \mathrm{~h} /$ day for 30 continuous days. The results showed that the level of NO in the mouse brain gradually increased with prolonged radiation time (73). NO can pass through cell membranes by lipophilicity but is not released in the form of exocytosis; it acts through chemical reactions before becoming inactivated. In addition, NO can react with other free radicals and d-orbitals of transition metals. The most common for the latter is the interaction of $\mathrm{NO}$ with iron, because iron acts as a key component of abundant proteins, especially hemeproteins, involved in numerous physiological processes. Burlaka et al. exposed animals to ultrahigh frequency EMR of the non-thermal spectrum using the generator "Volna" (Ukraine) with impulse modulation and the following parameters: pulse duration $2 \mathrm{~ms}$, pulse separation $10 \mathrm{~ms}$, carrier frequency 0.465 $\mathrm{GHz}$, and exposure duration $17.5 \mathrm{~min}$. The energy flux density in the exposure area was $1.0-6.0 \mathrm{~mW} / \mathrm{cm}^{2}$. Ultrahigh frequency EMR resulted in a significant increase in the level of NO synthesis in the mitochondria of neural cells in animal brain tissue and a significant increase in the activity of mitochondrial NO synthase (32). Considering the toxic effect of high NO concentrations on cells, the increase in NO may cause neuronal damage, which in turn leads to a decrease in learning and memory ability in mice.

\section{POSSIBLE MECHANISMS UNDERLYING NEUROTRANSMITTER CHANGES CAUSED BY EMR}

\section{Electrophysiological Changes}

Neurophysiological mechanisms especially electrophysiological changes would lead to better understanding the neurotransmitter changes associated with EMR exposure. Several neuroimaging methods are used to illuminate the interference between brain electrical activity and EMR. For example, the changes of extracellular electrical potential in the cortex can be measured by EEG techniques, the regional changes of blood oxygen utilization can be detected with functional magnetic resonance imaging (fMRI) method during neuropsychological performance, and positron emission tomography (PET) reflects the cerebral metabolism $(43,74-76)$. Brain electrical activity originates from the fluctuation of membrane potential in the neuron. The transduction of a nerve impulse results in the postsynaptic potential and the following synaptic transmission, which could reflect the modulation of neurotransmission.

Many studies indicate an increase of cortical excitability and/or efficiency during EMR exposure, and this electrical activity changes may persist for several minutes post-exposure. In addition, an increase of cerebral metabolism (PET), a decrease of alpha activity, an increase of high beta and gamma frequency activity, increased reaction time, and disrupted sleep EEG were also induced by EMR exposure (77-82). Based on several methodologies, such as fMRI, PET, EMF-elicited event-related potentials (ERPs) $(83,84)$, and event-related desynchronization (ERD), and interhemispheric synchronization, frontal and temporal regions appear to be more susceptible $(76,81,82$, 85-87). In terms of the EMF-induced effects on cortical excitability and efficiency, several factors have been proposed, including alteration of dependent $\mathrm{Na}-\mathrm{K}$ trans-membrane ionic channels, changes of cellular calcium homeostasis, increased cellular excitability, and modulation of cellular response to stress $(86,87)$. However, several inconsistent findings exist, and the heterogeneity of results may be due to methodological differences, statistical power, and interpretation criteria (88). Altogether, the abnormal brain electrical activity may reflect the modulation of neurotransmission induced by EMR, and result in the changes of neurotransmitters.

\section{Cell Membrane Damage}

It is known that membrane is the first and an important target of EMF in cells. Cell membrane damage might result in neurotransmitter changes in the brain. Understanding the effects of EMR on neurotransmitters is critical for further determining the targets of EMR in cells. EMR can alter cell membrane permeability such as changes in calcium, ionic distribution and ion permeability (89). Calcium is one of the important signaling substances, and an imbalance of calcium homeostasis can alter many functions of the cell. Previous studies have showed that EMR exposure can alter the calcium channels and receptors on the cell membrane, and influence transport of calcium ions over the cell membrane, which play an important role in cell signaling pathways, and in turn may affect the response of neurotransmitters $(90,91)$. It was reported that the number of opened calcium channel increased with the presence of EMFs, which might resulting in the increased intracellular calcium concentration under EMR exposure (92). In addition, the changes of intracellular calcium levels can trigger unusual synaptic action or cause neuronal apoptosis. This in turn can exert an influence on the neurotransmission of learning and memory process (93).

Additionally, the enhanced activity of voltage-gated calcium channels (VGCCs) have been delineated, after exposure to EMR in many cell types (94-96). Previous studies used the activity of VGCCs as an indicator of microwave radiation induced changes in ion channels $(96,97)$. The level of neurotransmitters can indicate the membrane properties, such as the expression level of synaptic vesicular-associated proteins, can indicate the function of the synaptic vesicular membrane $(22,98)$. It was reported that, EMR activation of VGCCs causes a rapid increase in intracellular calcium, nitric oxide, and peroxynitrite (99). However, a recent study on the effects of $2.856 \mathrm{GHz}$ pulsed microwave radiation in the primary hippocampal neurons, reported that the total cellular calcium, the levels of calcium in endoplasmic reticulum and mitochondria all decreased after microwave exposure, suggesting calcium efflux during microwave radiation (100). Although many animal studies have suggested about the effects of EMR on 
the calcium efflux and influx in the neurons (101-103), the results regarding the effects of EMR on the membrane integrity and permeability are still unclear. The changes of membrane permeability may result in the damage of membrane integrity, and lead to the changes in brain neurotransmitter imbalance. In this regard, further studies by various duration and dose of EMR are needed to investigate the effects of EMR on the relationship of neurotransmitters and cell membrane permeability.

\section{Abnormal Signal Transduction}

It is known that neurotransmitter and its receptors are involved in various signaling related to cell proliferation, apoptosis, differentiation and inflammation. The crosstalk between neurotransmission and cell signaling may in turn affect the metabolism and transport of neurotransmitters. EMR exposures produce the main pathophysiological effects via excessive calcium signaling and the peroxynitrite pathway, and the diverse non-thermal effects of EMR are produced via VGCC activation (104). As the energy source of the cell, the mitochondrial calcium reaction was influenced by the alterations in calcium signaling pathways in response to the effects of EMR exposure (90). In addition to calcium signaling changes, EMR can cause activation of free radical processes and overproduction of reactive oxygen species (ROS) in neurons $(53,104-108)$. Due to the dependent on oxidative phosphorylation for energy, neurons are vulnerable for oxidative stress compared to other cells. During EMR exposure, the occurrence of oxidant-antioxidant imbalance in the brain leads to oxidative stress (109). Both NO and superoxide $\left(\mathrm{O}_{2}^{-}\right)$are elevated by increased calcium, resulting in the increase of peroxynitrite $\left(\mathrm{ONOO}^{-}\right)$levels. The various oxidants act to produce greatly elevated NF-kappa B (NF-кB) activity, leading to inflammation (110). In addition, NF- $\kappa$ B signaling is reported to be involved in neural immune response, synaptic plasticity, learning and memory, neuroprotection and neurodegeneration $(111,112)$. It has been shown that EMR exposure leads to up-regulated elements belonging to apoptotic pathways, which results in neuronal apoptosis $(113,114)$. The probable mechanisms are mainly attributed to increased ROS generation following EMR exposure.

The energy of non-ionizing radiation is not enough to directly break chemical bonds, and therefore the occurrence of DNA damage with non-ionizing EMR exposures is primarily a consequence of generation of ROS, followed by oxidative stress. Numerous animal experiments have clearly demonstrated that non-thermal EMR can cause oxidative stress (115, 116), particularly in the brain (3, 117-119). It has been documented that non-thermal EMR exposure of $900 \mathrm{MHz}$ or $2.45 \mathrm{GHz}$ in rats, either short-term or long-term, can trigger neuronal dysfunction and apoptosis of hippocampal pyramidal cells $(117,120)$ and cerebellum Purkinje cells (121) through induction of oxidative stress. In addition, the mitogenactivated phosphokinase (MAPK) pathway plays a key role in cell proliferation and metabolism. The phosphorylation of transcription factors in the downstream occurs after activation of the MAPK cascades pathway $(89,122)$. The proliferation and survival of different cell types can be stimulated by low concentrations of free radicals. The effects of ROS on cell proliferation, is an important secondary messenger in the physiological process, and ROS plays a key role in the regulation of cytosolic calcium homeostasis. The protein phosphorylation and activation of the AP-1 family factors and nuclear factor kappa B (NF- $\mathrm{B})$ is regulated by the level of cytosolic calcium (123). Activation of the protein kinases pathways regulates the physiological response to EMR exposure including neurotransmitter imbalance, but the detailed mechanisms are still unclear.

\section{DISCUSSION}

According to the time duration of EMR exposure, we divided all the references including neurotransmitter measurement in the brain into two groups: short-term (within one week) exposure and long-term (more than one week) exposure groups. It is apparent from the listed reference in Tables 1, 2 that, no obvious difference was observed for neurotransmitter changes between the short-term (Table 1) and long-term (Table 2) EMR exposure. It is known that the response to non-thermal EMR depends on both power density and duration of exposure. Some studies show no effect under fixed short-term EMR exposures, but this does not imply no effects under longer-term exposures $(5,124)$. In a recent review, Leach et al. analyzed 2,653 papers captured in the database examine the bioeffect outcomes in the $300 \mathrm{MHz}-3$ $\mathrm{GHz}$ range. The results showed three times more biological "Effect" than "No Effect" papers (125). Although some studies report no effect on the tested indicators, there are studies find the significant effect in many cases. This inconsistency might due to the lack of replication between studies. It is challenging for undertaking a literature review or comparing findings between relevant scientific papers, due to the subject, various experimental methodology and changing exposure parameters in the available studies. Notwithstanding animal models can only provide a strong indication of risks to humans, and the exchange formula or conversion rules between animal studies and human biological effects are far from clarified. The development of reliable safety standards has analyzed such parameters as power density, dose, and duration of exposure, and this would protect against the detrimental health effects of EMR exposure at nonthermal intensities.

Many evidences indicate that EMR alter several aspects of calcium function in cells. In spite of numerous studies reporting altered calcium metabolism upon exposure to radiofrequency electromagnetic fields, the underlying mechanisms of these effects are still not clear. However, some studies have suggested that the calcium activation could be the initial event leading to alteration in protein configuration, followed by generation of ROS and ultimately activation of the molecular apoptosis pathways (101). Lushchak et al. reported that EMR exposure may firstly produce the free radicals in the brain and later they are converted to ROS (126). The elevation of ROS level can attack various biomolecules in the cell. The raised ROS can also in turn trigger calcium release, and then activate the genetic factors leading to DNA damage (110). Any alteration in gene and enzyme levels, may result in the activation of 


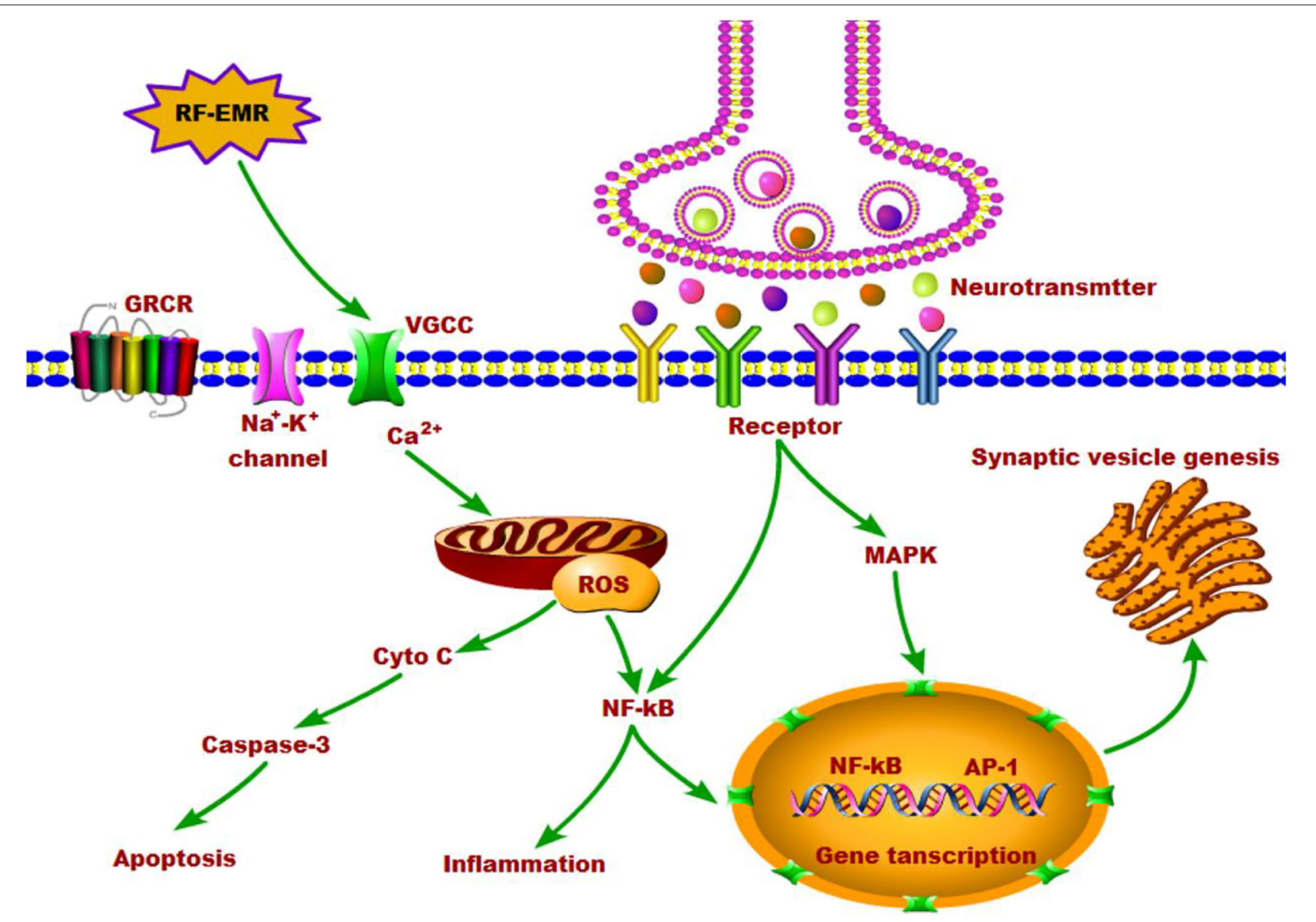

FIGURE 1 | The effects of RF-EMR exposure on neurotransmitters in the brain and the possible underlying mechanisms.

downstream signaling (114), particularly the mitochondriadependent caspase-3 pathway can cause the apoptosis of neurons $(113,127)$, which would lead to altered behavioral manifestations and pathophysiological changes in the brain. In a word, EMR exposure does increases the intracellular calcium and the formation of ROS, which would alter the cellular function eventually and lead to numerous biological effects including neurotransmitter imbalance. We summarized the effects of EMR on neurotransmitters in the brain and the possible underlying mechanisms in Figure 1.

Though we narrow down to biochemical imbalance to simplify explanation for changes of each neurotransmitter, the combined effects of neurotransmitters still deserves attention. It is also possible that the various neurotransmission effects following EMR exposure in animals might be due to combined effects in various brain regions, such as neurophysiological changes, increase of calcium and ROS, and thereby cell membrane damage and the downstream signaling changes. An imbalance in the excitation-inhibition imbalance of neurons resulting from neurotransmitter changes, would alter behavior, and it might do so without evident structural changes. Currently, the neurochemical mechanisms of EMR exposure are still unclear. Further study in this regard is needed and will reveal much clearer picture of brain mechanisms caused by EMR.

\section{CONCLUSION}

In summary, research on the synthesis, metabolism and transport of neurotransmitters in the brain by EMR is increasing gradually, but due to the different parameters of EMR, experimental objects and conditions, the experimental results are not very consistent and comparative. Therefore, the effects of EMR on the metabolism and transport of neurotransmitters have not been clarified. Moreover, the role of neurotransmitters and their mechanism in the neurobehavioral dysfunction induced by EMR have not been revealed. Further detailed studies are needed. On the other hand, because of the complex diversity of neurotransmitters in the brain, the interaction, cotransmission and coregulation of neurotransmitters make it difficult to distinguish the primary and secondary changes of each neurotransmitter. Furthermore, the interaction of different neural nuclei in the brain constitutes sophisticated neural circuits, which is the fundamental basis of how the brain performs functions. Consequently, the regulation of neural 
circuits may be involved in the neurotransmitter disorder of the brain induced by EMR.

\section{FUTURE PERSPECTIVES}

Recently, novel techniques in brain science, such as neuroviral tracers, neuroimaging and neuroelectrophysiology, have been rapidly developed. These techniques were devised especially for the development and wide application of brain intervention techniques, including optogenetics and chemical genetics. Moreover, these advances have provided new methods to study the neurobiological effects of EMR at the neural circuit level. Notably, the G-protein-coupled receptor activation-based (GRAB) sensor can directly measure neurotransmitter release and monitor the activity of neurotransmission in vivo (128). Combined with fiber photometry recording, the GRAB sensor enables sensitive detection of single-trial neurotransmitter dynamics in multiple brain regions in mice performing a variety

\section{REFERENCES}

1. Wei YW, Yang JY, Chen ZY, Wu TN, Lv B. Modulation of resting-state brain functional connectivity by exposure to acute fourth-generation long-term evolution electromagnetic field: An fMRI study. Bioelectromagnetics. (2019) 40:42-51. doi: 10.1002/bem.22165

2. Yang L, Zhang C, Chen ZY Li CS, Wu TN. Functional and network analyses of human exposure to long-term evolution signal. Environ Sci Pollut Res Int. (2021) 28:5755-73. doi: 10.1007/s11356-020-10728-w

3. Megha K, Deshmukh PS, Banerjee BD, Tripathi AK, Ahmed R, Abegaonkar MP. Low intensity microwave radiation induced oxidative stress, inflammatory response and DNA damage in rat brain. Neurotoxicology. (2015) 51:158-65. doi: 10.1016/j.neuro.2015.10.009

4. Saikhedkar N, Bhatnagar M, Jain A, Sukhwal P, Sharma C, Jaiswal $\mathrm{N}$. Effects of mobile phone radiation ( $900 \mathrm{MHz}$ radiofrequency) on structure and functions of rat brain. Neurol Res. (2014) 36:1072-9. doi: 10.1179/1743132814Y.0000000392

5. Belpomme D, Hardell L, Belyaev I, Burgio E, Carpenter DO. Thermal and non-thermal health effects of low intensity non-ionizing radiation: An international perspective. Environ Pollut. (2018) 242:643-58. doi: 10.1016/j.envpol.2018.07.019

6. Zhi WJ, Wang LF, Hu XJ. Recent advances in the effects of microwave radiation on brains. Mil Med Res. (2017) 4:29. doi: 10.1186/s40779-017-0139-0

7. Comelekoglu U, Aktas S, Demirbag B, Karagul MI, Yalin S, Yildirim M, et al. Effect of low-level $1800 \mathrm{MHz}$ radiofrequency radiation on the rat sciatic nerve and the protective role of paricalcitol. Bioelectromagnetics. (2018) 39:631-43. doi: 10.1002/bem.22149

8. Eris AH, Kiziltan HS, Meral I, Genc H, Trabzon M, Seyithanoglu H, et al. Effect of Short-term $900 \mathrm{MHz}$ low level electromagnetic radiation exposure on blood serotonin and glutamate levels. Bratisl Lek Listy. (2015) 116:101-3. doi: 10.4149/BLL_2015_019

9. Noor NA, Mohammed HS, Ahmed NA, Radwan NM. Variations in amino acid neurotransmitters in some brain areas of adult and young male albino rats due to exposure to mobile phone radiation. Eur Rev Med Pharmacol Sci. (2011) 15:729-42.

10. Ferreri F, Curcio G, Pasqualetti P, De Gennaro L, Fini R, Rossini PM. Mobile phone emissions and human brain excitability. Ann Neurol. (2006) 60:188-96. doi: 10.1002/ana.20906

11. Tuszynski J, Tilli TM, Levin M. Ion Channel and Neurotransmitter Modulators as Electroceutical Approaches to the Control of Cancer. Curr Pharm Des. (2017) 23:4827-41. doi: 10.2174/13816128236661705301 05837 of behaviors (82). With these new techniques in neuroscience, studying the effects of EMR on neurotransmitter metabolism and the transport of neurotransmitters at the neural circuit level is expected to overcome the challenges inherent in investigating the neurobiological effect of EMR and its mechanisms and open novel pathways for the exploration of preventive targets and interventions.

\section{AUTHOR CONTRIBUTIONS}

$\mathrm{CH}$ wrote the paper and outlined this manuscript. $\mathrm{HZ}$ and $\mathrm{YL}$ provided a detailed guidance throughout the article. All the authors read and approved the final manuscript.

\section{FUNDING}

This work was supported by the National Natural Science Foundation of China (81472951).
12. Ng J, Heales SJ, Kurian MA. Clinical features and pharmacotherapy of childhood monoamine neurotransmitter disorders. Paediatr Drugs. (2014) 16:275-91. doi: 10.1007/s40272-014-0079-z

13. Sheffler ZM, Reddy V, Pillarisetty LS. Physiology, Neurotransmitters. Treasure Island, FL: StatPearls Publishing (2021).

14. Aboul Ezz HS, Khadrawy YA, Ahmed NA, Radwan NM, El Bakry MM. The effect of pulsed electromagnetic radiation from mobile phone on the levels of monoamine neurotransmitters in four different areas of rat brain. Eur Rev Med Pharmacol Sci. (2013) 17:1782-8.

15. Inaba $\mathrm{R}$, Shishido K, Okada A, Moroji T. Effects of whole body microwave exposure on the rat brain contents of biogenic amines. Eur J Appl Physiol Occup Physiol. (1992) 65:124-8. doi: 10.1007/BF00705068

16. Ishikawa K, Shibanoki S, Saito S, McGaugh JL. Effect of microwave irradiation on monoamine metabolism in dissected rat brain. Brain Res. (1982) 240:158-61. doi: 10.1016/0006-8993(82)90655-2

17. Karri V, Schuhmacher M, Kumar V. Heavy metals ( $\mathrm{Pb}, \mathrm{Cd}$, As and $\mathrm{MeHg}$ ) as risk factors for cognitive dysfunction: A general review of metal mixture mechanism in brain. Environ Toxicol Pharmacol. (2016) 48:203-13. doi: 10.1016/j.etap.2016.09.016

18. Mausset-Bonnefont AL, Hirbec H, Bonnefont X, Privat A, Vignon J, de Sèze R. Acute exposure to GSM 900-MHz electromagnetic fields induces glial reactivity and biochemical modifications in the rat brain. Neurobiol Dis. (2004) 17:445-54. doi: 10.1016/j.nbd.2004.07.004

19. Zhang YW Yu ZP, Xie Y, Fang Q. Effects of microwave irradiation on NMDA receptor subunits mRNA expressions in rat hippocampus. J Hygiene Res. (2008) 37:25-8.

20. Wang LF, Tian DW Li HJ, Gao YB, Wang CZ, Zhao L, Zuo HY, et al. Identification of a novel rat NR2B subunit gene promoter region variant and its association with microwave-induced neuron impairment. Mol Neurobiol. (2016) 53:2100-11. doi: 10.1007/s12035-015-9169-3

21. Xiong L, Sun CF, Zhang J, Gao YB, Wang LF, Zuo HY, et al. Microwave exposure impairs synaptic plasticity in the rat hippocampus and PC12 cells through over-activation of the NMDA receptor signaling pathway. Biomed Environ Sci. (2015) 28:13-24. doi: 10.3967/bes2015.002

22. Qiao SM, Peng RY, Yan HT, Gao YB, Wang CZ, Wang SM, et al. Reduction of phosphorylated synapsin I (ser-553) leads to spatial memory impairment by attenuating GABA release after microwave exposure in Wistar rats. PLoS ONE. (2014) 9:e95503. doi: 10.1371/journal.pone.00 95503

23. Wang H, Peng RY, Zhao L, Wang SM, Gao YB, Wang LF, et al. The relationship between NMDA receptors and microwave-induced learning and memory impairment: a long-term observation on Wistar rats. Int J Radiat Biol. (2015) 91:262-9. doi: 10.3109/09553002.2014.988893 
24. Wang Q, Cao ZJ, Bai XT. Effect of $900 \mathrm{MHz}$ electromagnetic fields on the expression of GABA receptor of cerebral cortical neurons in postnatal rats. $J$ Hygiene Res. (2005) 34:546-68.

25. Fujiwara M, Watanabe Y, Katayama Y, Shirakabe Y. Application of highpowered microwave irradiation for acetylcholine analysis in mouse brain. Eur J Pharmacol. (1978) 51:299-301. doi: 10.1016/0014-2999(78)90416-8

26. Lai H, Carino MA, Horita A, Guy AW. Low-level microwave irradiation and central cholinergic systems. Pharmacol Biochem Behav. (1989) 33:131-8. doi: 10.1016/0091-3057(89)90442-5

27. Krylova IN, Dukhanin AS. Il'in AB, Kuznetsova EIu, Balaeva NV, Shimanovskii NL, Pal'tsev IuP, Iasnetsov VV. The effect of ultrahighfrequency electromagnetic radiation on learning and memory processes. Biull Eksp Biol Med. (1992) 114:483-4. doi: 10.1007/BF00837653

28. Testylier G, Tonduli L, Malabiau R, Debouzy JC. Effects of exposure to low level radiofrequency fields on acetylcholine release in hippocampus of freely moving rats. Bioelectromagnetics. (2002) 23:249-55. doi: 10.1002/bem.10008

29. Lai H, Horita A, Guy AW. Acute low-level microwave exposure and central cholinergic activity: studies on irradiation parameters. Bioelectromagnetics. (1988) 9:355-62. doi: 10.1002/bem.2250090405

30. Lai H, Carino MA, Horita A, Guy AW. Opioid receptor subtypes that mediate a microwave-induced decrease in central cholinergic activity in the rat. Bioelectromagnetics. (1992) 13:237-46. doi: 10.1002/bem.2250130308

31. Lai H, Horita A, Guy AW. Microwave irradiation affects radial-arm maze performance in the rat. Bioelectromagnetics. (1994) 15:95-104. doi: 10.1002/bem.2250150202

32. Burlaka AP, Druzhyna MO, Vovk AV. Lukin SM. Disordered redox metabolism of brain cells in rats exposed to low doses of ionizing radiation or UHF electromagnetic radiation. Exp Oncol. (2016) 38:238-41. doi: 10.31768/2312-8852.2016.38(4):238-241

33. Kim JH, Lee CH, Kim HG, Kim HR. Decreased dopamine in striatum and difficult locomotor recovery from MPTP insult after exposure to radiofrequency electromagnetic fields. Sci Rep. (2019) 9:1201. doi: 10.1038/s41598-018-37874-Z

34. Maaroufi K, Had-Aissouni L, Melon C, Sakly M, Abdelmelek H, Poucet B, et al. Spatial learning, monoamines and oxidative stress in rats exposed to 900 $\mathrm{MHz}$ electromagnetic field in combination with iron overload. Behav Brain Res. (2014) 258:80-9. doi: 10.1016/j.bbr.2013.10.016

35. Ji J, Zhang YH, Yang XQ, Jiang RP, Guo DM, Cui X. The influence of microwave radiation from cellular phone on fetal rat brain. Electromagn Biol Med. (2012) 31:57-66. doi: 10.3109/15368378.2011.624652

36. Megha K, Deshmukh PS, Ravi AK, Tripathi AK, Abegaonkar MP, Banerjee BD. Effect of low-intensity microwave radiation on monoamine neurotransmitters and their key regulating enzymes in rat brain. Cell Biochem Biophys. (2015) 73:93-100. doi: 10.1007/s12013-015-0576-x

37. Cao Z, Zhang H, Tao Y, Liu J. Effects of microwave radiation on lipid peroxidation and the content of neurotransmitters in mice. J Hygiene Res. (2000) 30:28-9.

38. Li HJ, Peng RY, Wang CZ, Qiao SM, Yong Z, Gao YB, et al. Alterations of cognitive function and 5-HT system in rats after long term microwave exposure. Physiol Behav. (2015) 140:236-46. doi: 10.1016/j.physbeh.2014.12.039

39. Ahmed NA, Radwan NM, Aboul Ezz HS, Khadrawy YA, Salama NA. The chronic effect of pulsed $1800 \mathrm{MHz}$ electromagnetic radiation on amino acid neurotransmitters in three different areas of juvenile and young adult rat brain. Toxicol Ind Health. (2018) 34:860-72. doi: 10.1177/0748233718798975

40. Zhao L, Peng RY, Wang SM, Wang LF, Gao YB, Dong J, et al. Relationship between cognition function and hippocampus structure after long-term microwave exposure. Biomed Environ Sci. (2012) 25:182-8. doi: 10.3967/0895-3988.2012.02.009

41. Wang H, Tan SZ, Xu XP, Zhao L, Zhang J, Yao BW, et al. Long term impairment of cognitive functions and alterations of NMDAR subunits after continuous microwave exposure. Physiol Behav. (2017) 181:1-9. doi: 10.1016/j.physbeh.2017.08.022

42. Huang CT, Liu P, Wu HX, Wang JL, Wu XN. Effects of NMDA receptor expression in rat's hippocampus after exposure to $1800 \mathrm{MHz}$ radiofrequency field. Zhonghua Yu Fang Yi Xue Za Zhi. (2006) 40:21-4.

43. Zhang J, Sumich A, Wang GY. Acute effects of radiofrequency electromagnetic field emitted by mobile phone on brain function. Bioelectromagnetics. (2017) 38:329-38. doi: 10.1002/bem. 22052

44. Kumar M, Singh SP, Chaturvedi CM. Chronic nonmodulated microwave radiations in mice produce anxiety-like and depression-like behaviours and calcium- and NO-related biochemical changes in the brain. Exp Neurobiol. (2016) 25:318-27. doi: 10.5607/en.2016.25.6.318

45. Gökçek-Saraç Ç, Akçay G, Karakurt S, Ateş K, Özen S, Derin N. Possible effects of different doses of 2. $1 \mathrm{GHz}$ electromagnetic radiation on learning, and hippocampal levels of cholinergic biomarkers in Wistar rats. Electromagn Biol Med. (2021) 40:179-90. doi: 10.1080/15368378.2020.1851251

46. Gupta SK, Mesharam MK, Krishnamurthy S. Electromagnetic radiation 2450 $\mathrm{MHz}$ exposure causes cognition deficit with mitochondrial dysfunction and activation of intrinsic pathway of apoptosis in rats. J Biosci. (2018) 43:263-76. doi: 10.1007/s12038-018-9744-7

47. Kunjilwar KK, Behari J. Effect of amplitude-modulated radio frequency radiation on cholinergic system of developing rats. Brain Res. (1993) 601:321-4. doi: 10.1016/0006-8993(93)91729-c

48. Qin FJ, Nie JH, Cao Y, Li JX, Tong J. Influence of computer electromagnetic radiation on learning and memory ability as well as cerebra neuron transmitter of mice. J Radiat Res. (2010) 28:185-9. Available online at: https:// kns.cnki.net/kcms/detail/detail.aspx?

49. Kasture AS, Hummel T, Sucic S, Freissmuth M. Big Lessons from tiny flies: drosophila melanogaster as a model to explore dysfunction of dopaminergic and serotonergic neurotransmitter systems. Int J Mol Sci. (2018) 19:1788. doi: 10.3390/ijms19061788

50. Gilman AG, Goodman LS, Gilman A. Goodman and Gilman's The Pharmacological Basis of Therapeutics. 6th ed. New York: Macmillan Publishing Co. Inc. 1980; 476.

51. Davis KL, Kahn RS, Ko G, Davidson M. Dopamine in schizophrenia: a review and reconceptualization. Am J Psychiatry. (1991) 148:1474-86. doi: 10.1176/ajp.148.11.1474

52. Abi-Dargham A. From "bedside" to "bench" and back: A translational approach to studying dopamine dysfunction in schizophrenia. Neurosci Biobehav Rev. (2020) 110:174-9. doi: 10.1016/j.neubiorev.2018.12.003

53. Silverberg AB, Shah SD, Haymond MW, Cryer PE. Norepinephrine: hormone and neurotransmitter in man. Am J Physiol. (1978) 234:252-56. doi: 10.1152/ajpendo.1978.234.3.E252

54. Zhu ZJ, Cheng CC, Chang C, Ren GH, Zhang JB, Peng Y, et al. Characteristic fingerprint spectrum of neurotransmitter norepinephrine with broadband terahertz time-domain spectroscopy. Analyst. (2019) 144:2504-10. doi: 10.1039/C8AN02079E

55. Charnay Y, Léger L. Brain serotonergic circuitries. Dialogues Clin Neurosci. (2010) 12:471-87. doi: 10.31887/DCNS.2010.12.4/ycharnay

56. Petkov VD, Konstantinova E. Effects of the ergot alkaloid elymoclavine on the level and turnover of biogenic monoamines in the rat brain. Arch Int Pharmacodyn Ther. (1986) 281:22-34.

57. Lai YF, Wang HY, Peng RY. Establishment of injury models in studies of biological effects induced by microwave radiation. Mil Med Res. (2021) 8:12. doi: 10.1186/s40779-021-00303-w

58. Pellerin L, Magistretti PJ. Neuroenergetics: calling upon astrocytes to satisfy hungry neurons. Neuroscientist. (2004) 10:53-62. doi: $10.1177 / 1073858403260159$

59. Shen J, Petersen KF, Behar KL, Brown P, Nixon TW, Mason GF, et al. Determination of the rate of the glutamate/glutamine cycle in the human brain by in vivo 13C NMR. Proc Natl Acad Sci U S A. (1999) 96:8235-40. doi: 10.1073/pnas.96.14.8235

60. Niciu MJ, Kelmendi B, Sanacora G. Overview of glutamatergic neurotransmission in the nervous system. Pharmacol Biochem Behav. (2012) 100:656-64. doi: 10.1016/j.pbb.2011.08.008

61. Rebola N, Srikumar BN, Mulle C. Activity-dependent synaptic plasticity of NMDA receptors. J Physiol. (2010) 588:93-9. doi: 10.1113/jphysiol.2009.179382

62. Chater TE, Goda Y. The role of AMPA receptors in postsynaptic mechanisms of synaptic plasticity. Front Cell Neurosci. (2014) 27:401. doi: 10.3389/fncel.2014.00401

63. Stone E, Haario $\mathrm{H}$, Lawrence JJ, A. kinetic model for the frequency dependence of cholinergic modulation at hippocampal GABAergic 
synapses. Math Biosci. (2014) 258:162-75. doi: 10.1016/j.mbs.2014. 09.013

64. Lawrence JJ. Cholinergic control of GABA release: emerging parallels between neocortex and hippocampus. Trends Neurosci. (2008) 31:317-27. doi: 10.1016/j.tins.2008.03.008

65. Fedotcheva NI, Sokolov AP, Kondrashova MN. Nonezymatic formation of succinate in mitochondria under oxidative stress. Free Radic Biol Med. (2006) 41:56-64. doi: 10.1016/j.freeradbiomed.2006. 02.012

66. Zhang JP, Zhang KY, Guo L, Chen QL, Gao P, Wang T, et al. Effects of 1. $8 \mathrm{GHz}$ Radiofrequency Fields on the Emotional Behavior and Spatial Memory of Adolescent Mice. Int J Environ Res Public Health. (2017) 14:1344. doi: 10.3390/ijerph14111344

67. Stein V, Nicoll RA, GABA. generates excitement. Neuron. (2003) 37:375-8. doi: 10.1016/S0896-6273(03)00056-4

68. Li XN Yu B, Sun QT, Zhang YL, Ren M, Zhang XY, et al. Generation of a whole-brain atlas for the cholinergic system and mesoscopic projectome analysis of basal forebrain cholinergic neurons. Proc Natl Acad Sci U S A. (2018) 115:415-20. doi: 10.1073/pnas.1703601115

69. Dannenberg H, Young K, Hasselmo M. Modulation of hippocampal circuits by muscarinic and nicotinic receptors. Front Neural Circuits. (2017) 13:102. doi: 10.3389/fncir.2017.00102

70. Hassanshahi A, Shafeie SA, Fatemi I, Hassanshahi E, Allahtavakoli M, Shabani M, et al. The effect of Wi-Fi electromagnetic waves in unimodal and multimodal object recognition tasks in male rats. Neurol Sci. (2017) 38:1069-76. doi: 10.1007/s10072-017-2920-y

71. Shang Y, Filizola M. Opioid receptors: Structural and mechanistic insights into pharmacology and signaling. Eur J Pharmacol. (2015) 763:206-13. doi: 10.1016/j.ejphar.2015.05.012

72. Kirichuk VF, Ivanov AN, Kirijazi TS. Correction of microcirculatory disturbances with terahertz electromagnetic radiation at nitric oxide frequencies in albino rats under conditions of acute stress. Bull Exp Biol Med. (2011) 151:288-91. doi: 10.1007/s10517-011-1311-2

73. Curcio G, Nardo D, Perrucci MG, Pasqualetti P, Chen TL, Del Gratta $\mathrm{C}$, et al. Effects of mobile phone signals over BOLD response while performing a cognitive task. Clin Neurophysiol. (2012) 123:129-36. doi: 10.1016/j.clinph.2011.06.007

74. Berger A. How does it work? Positron emission tomography. BMJ. (2003) 326:1449. doi: 10.1136/bmj.326.7404.1449

75. Wang GY, Kydd R, Russell BR. Auditory event-related potentials in methadone substituted opiate users. J Psychopharmacol. (2015) 29:983-95. doi: 10.1177/0269881115587929

76. Volkow ND, Tomasi D, Wang GJ, Vaska P, Fowler JS, Telang F, et al. Effects of cell phone radiofrequency signal exposure on brain glucose metabolism. JAMA. (2011) 305:808-13. doi: 10.1001/jama.201 1.186

77. Lowden A, Akerstedt T, Ingre M, Wiholm C, Hillert L, Kuster N, et al. Sleep after mobile phone exposure in subjects with mobile phonerelated symptoms. Bioelectromagnetics. (2011) 32:4-14. doi: 10.1002/bem. 20609

78. Schmid MR, Loughran SP, Regel SJ, Murbach M, Bratic Grunauer A, Rusterholz T, et al. Sleep EEG alterations: effects of different pulsemodulated radio frequency electromagnetic fields. J Sleep Res. (2012) 21:508. doi: 10.1111/j.1365-2869.2011.00918.x

79. Schmid MR, Murbach M, Lustenberger C, Maire M, Kuster N, Achermann P, et al. Sleep EEG alterations: effects of pulsed magnetic fields versus pulse-modulated radio frequency electromagnetic fields. J Sleep Res. (2012) 21:620-9. doi: 10.1111/j.1365-2869.2012.01025.x

80. Ghosn R, Yahia-Cherif L, Hugueville L, Ducorps A, Lemaréchal JD, Thuróczy G, et al. Radiofrequency signal affects alpha band in resting electroencephalogram. J Neurophysiol. (2015) 113:2753-9. doi: 10.1152/jn.00765.2014

81. Roggeveen S, van Os J, Viechtbauer W, Lousberg R, EEG. Changes due to experimentally induced $3 \mathrm{~g}$ mobile phone radiation. PLoS ONE. (2015) 10:e0129496. doi: 10.1371/journal.pone.0129496

82. Carrubba S, Frilot C. 2nd, Chesson AL Jr, Marino AA. Mobilephone pulse triggers evoked potentials. Neurosci Lett. (2010) 469:164-8. doi: 10.1016/j.neulet.2009.11.068
83. Carrubba S, Marino AA. The effects of low-frequency environmentalstrength electromagnetic fields on brain electrical activity: a critical review of the literature. Electromagn Biol Med. (2008) 27:83-101. doi: 10.1080/15368370802088758

84. Roggeveen S, van Os J, Lousberg R. Does the brain detect $3 \mathrm{G}$ mobile phone radiation peaks? An explorative in-depth analysis of an experimental study. PLoS ONE. (2015) 10:e0125390. doi: 10.1371/journal.pone.0125390

85. Vecchio F, Buffo P, Sergio S, Iacoviello D, Rossini PM, Babiloni C. Mobile phone emission modulates event-related desynchronization of $\alpha$ rhythms and cognitive-motor performance in healthy humans. Clin Neurophysiol. (2012) 123:121-8. doi: 10.1016/j.clinph.2011.06.019

86. Vecchio F, Tombini M, Buffo P, Assenza G, Pellegrino G, Benvenga A, et al. Mobile phone emission increases inter-hemispheric functional coupling of electroencephalographic $\alpha$ rhythms in epileptic patients. Int J Psychophysiol. (2012) 84:164-71. doi: 10.1016/j.ijpsycho.2012.02.002

87. Valentini E, Ferrara M, Presaghi F, De Gennaro L, Curcio G. Systematic review and meta-analysis of psychomotor effects of mobile phone electromagnetic fields. Occup Environ Med. (2010) 67:708-16. doi: 10.1136/oem.2009.047027

88. Warille AA, Altun G, Elamin AA, Kaplan AA, Mohamed H, Yurt KK, et al. Skeptical approaches concerning the effect of exposure to electromagnetic fields on brain hormones and enzyme activities. J Microsc Ultrastruct. (2017) 5:177-84. doi: 10.1016/j.jmau.2017.09.002

89. Walleczek J. Electromagnetic field effects on cells of the immune system: the role of calcium signaling. FASEB J. (1992) 6:3177-85. doi: 10.1096/fasebj.6.13.1397839

90. Bauréus Koch CL, Sommarin M, Persson BR, Salford LG, Eberhardt JL. Interaction between weak low frequency magnetic fields and cell membranes. Bioelectromagnetics. (2003) 24:395-402. doi: 10.1002/bem.10136

91. Narayanan SN, Mohapatra N, John P. K N, Kumar RS, Nayak SB, Bhat PG. Radiofrequency electromagnetic radiation exposure effects on amygdala morphology, place preference behavior and brain caspase- 3 activity in rats. Environ Toxicol Pharmacol. (2018) 58:220-9. doi: 10.1016/j.etap.2018.01.009

92. Zhang YH, Zhan Y, Zhao TJ, Han YR, Liu H. Mechanism of permeation in calcium channels activation by applied magnetic fields. Annu Int Conf IEEE Eng Med Biol Soc. (2007) 2007:1391-3. doi: 10.1109/IEMBS.2007.4352558

93. Maskey D, Pradhan J, Aryal B, Lee CM, Choi IY, Park KS, et al. Chronic 835$\mathrm{MHz}$ radiofrequency exposure to mice hippocampus alters the distribution of calbindin and GFAP immunoreactivity. Brain Res. (2010) 1346:237-46. doi: 10.1016/j.brainres.2010.05.045

94. Papatheofanis FJ. Use of calcium channel antagonists as magnetoprotective agents. Radiat Res. (1990) 122:24-8. doi: 10.2307/3577578

95. Catterall WA. Structure and regulation of voltage-gated Ca2+ channels. Annu Rev Cell Dev Biol. (2000) 16:521-55. doi: 10.1146/annurev.cellbio.16.1.521

96. Pall ML. Electromagnetic fields act via activation of voltage-gated calcium channels to produce beneficial or adverse effects. J Cell Mol Med. (2013) 17:958-65. doi: 10.1111/jcmm.12088

97. Olgar Y, Hidisoglu E, Celen MC, Yamasan BE, Yargicoglu P, Ozdemir S. 2. $1 \mathrm{GHz}$ electromagnetic field does not change contractility and intracellular $\mathrm{Ca} 2+$ transients but decreases $\beta$-adrenergic responsiveness through nitric oxide signaling in rat ventricular myocytes. Int J Radiat Biol. (2015) 91:851-7. doi: 10.3109/09553002.2015.1068462

98. Wang LF, Peng RY, Hu XJ, Gao YB, Wang SM, Zhao L, et al. Abnormality of synaptic vesicular associated proteins in cerebral cortex and hippocampus after microwave exposure. Synapse. (2009) 63:1010-6. doi: 10.1002/syn.20684

99. Ledoigt G, Belpomme D. Cancer induction pathways and HF-EMF irradiation. Adv Biol Chem. (2013) 03:177-86. doi: 10.4236/abc.2013.32023

100. Wang H, Zhang J, Hu SH, Tan SZ, Zhang B, Zhou HM, et al. Realtime microwave exposure induces calcium efflux in primary hippocampal neurons and primary cardiomyocytes. Biomed Environ Sci. (2018) 31:561-71. doi: 10.3967/bes2018.077

101. Adey WR, Bawin SM, Lawrence AF. Effects of weak amplitude-modulated microwave fields on calcium efflux from awake cat cerebral cortex. Bioelectromagnetics. (1982) 3:295-307. doi: 10.1002/bem.2250030302

102. Dutta SK, Ghosh B, Blackman CF. Radiofrequency radiationinduced calcium ion efflux enhancement from human and other 
neuroblastoma cells in culture. Bioelectromagnetics. (1989) 10:197-202. doi: 10.1002/bem.2250100208

103. Dutta SK, Subramoniam A, Ghosh B, Parshad R. Microwave radiationinduced calcium ion efflux from human neuroblastoma cells in culture. Bioelectromagnetics. (1984) 5:71-8. doi: 10.1002/bem.2250050108

104. Pall ML, Wi-Fi. is an important threat to human health. Environ Res. (2018) 164:405-16. doi: 10.1016/j.envres.2018.01.035

105. Friedman J, Kraus S, Hauptman Y, Schiff Y, Seger R. Mechanism of shortterm ERK activation by electromagnetic fields at mobile phone frequencies. Biochem J. (2007) 405:559-68. doi: 10.1042/BJ20061653

106. Blank M, Goodman R. Electromagnetic fields stress living cells. Pathophysiology. (2009) 16:71-8. doi: 10.1016/j.pathophys.2009.01.006

107. Bilgici B, Akar A, Avci B, Tuncel OK. Effect of $900 \mathrm{MHz}$ radiofrequency radiation on oxidative stress in rat brain and serum. Electromagn Biol Med. (2013) 32:20-9. doi: 10.3109/15368378.2012.699012

108. Stein Y, Udasin IG. Electromagnetic hypersensitivity (EHS, microwave syndrome) - Review of mechanisms. Environ Res. (2020) 186:109445. doi: 10.1016/j.envres.2020.109445

109. Narayanan SN, Jetti R, Kesari KK, Kumar RS, Nayak SB, Bhat PG. Radiofrequency electromagnetic radiation-induced behavioral changes and their possible basis. Environ Sci Pollut Res Int. (2019) 26:30693-710. doi: 10.1007/s11356-019-06278-5

110. Görlach A, Bertram K, Hudecova S, Krizanova O. Calcium and ROS: A mutual interplay. Redox Biol. (2015) 6:260-71. doi: 10.1016/j.redox.2015.08.010

111. Kaltschmidt B, Widera D, Kaltschmidt C. Signaling via NF-kappaB in the nervous system. Biochim Biophys Acta. (2005) 1745:287-99. doi: 10.1016/j.bbamcr.2005.05.009

112. Kopitar-Jerala N. Innate Immune Response in Brain, NF-Kappa B Signaling and Cystatins. Front Mol Neurosci. (2015) 8:73. doi: 10.3389/fnmol.2015.00073

113. Zuo HY, Lin T, Wang DW, Peng RY, Wang SM, Gao YB, et al. Neural cell apoptosis induced by microwave exposure through mitochondria-dependent caspase-3 pathway. Int J Med Sci. (2014) 11:426-35. doi: 10.7150/ijms.6540

114. Zuo HY, Lin T, Wang DW, Peng RY, Wang SM, Gao YB, et al. RKIP regulates neural cell apoptosis induced by exposure to microwave radiation partly through the MEK/ERK/CREB pathway. Mol Neurobiol. (2015) 51:1520-9. doi: 10.1007/s12035-014-8831-5

115. Esmekaya MA, Ozer C, Seyhan N. $900 \mathrm{MHz}$ pulse-modulated radiofrequency radiation induces oxidative stress on heart, lung, testis and liver tissues. Gen Physiol Biophys. (2011) 30:84-9. doi: 10.4149/gpb_2011_01_84

116. Burlaka A, Tsybulin O, Sidorik E, Lukin S, Polishuk V, Tsehmistrenko S, et al. Overproduction of free radical species in embryonal cells exposed to low intensity radiofrequency radiation. Exp Oncol. (2013) 35:219-25.

117. Shahin S, Banerjee S, Swarup V, Singh SP, Chaturvedi CM. From the Cover: 2. 45-GHz Microwave Radiation Impairs Hippocampal Learning and Spatial Memory: Involvement of Local Stress Mechanism-Induced Suppression of iGluR/ERK/CREB Signaling. Toxicol Sci. (2018) 161:349-74. doi: $10.1093 /$ toxsci/kfx221

118. Dasdag S, Akdag MZ, Kizil G, Kizil M, Cakir DU, Yokus B. Effect of 900 $\mathrm{MHz}$ radio frequency radiation on beta amyloid protein, protein carbonyl, and malondialdehyde in the brain. Electromagn Biol Med. (2012) 31:67-74. doi: $10.3109 / 15368378.2011 .624654$
119. Furtado-Filho OV, Borba JB, Maraschin T, Souza LM, Henriques JA, Moreira JC, et al. Effects of chronic exposure to $950 \mathrm{MHz}$ ultra-high-frequency electromagnetic radiation on reactive oxygen species metabolism in the right and left cerebral cortex of young rats of different ages. Int J Radiat Biol. (2015) 91:891-7. doi: 10.3109/09553002.2015.1083629

120. Bas O, Odaci E, Kaplan S, Acer N, Ucok K, Colakoglu S. $900 \mathrm{MHz}$ electromagnetic field exposure affects qualitative and quantitative features of hippocampal pyramidal cells in the adult female rat. Brain Res. (2009) 1265:178-85. doi: 10.1016/j.brainres.2009.02.011

121. Sonmez OF, Odaci E, Bas O, Kaplan S. Purkinje cell number decreases in the adult female rat cerebellum following exposure to $900 \mathrm{MHz}$ electromagnetic field. Brain Res. (2010) 1356:95-101. doi: 10.1016/j.brainres.2010. 07.103

122. Ding GR, Yaguchi H, Yoshida M, Miyakoshi J. Increase in X-rayinduced mutations by exposure to magnetic field $(60 \mathrm{~Hz}, 5 \mathrm{mT})$ in NFkappaB-inhibited cells. Biochem Biophys Res Commun. (2000) 276:238-43. doi: $10.1006 /$ bbrc. 2000.3455

123. Storz P. Reactive oxygen species in tumor progression. Front Biosci. (2005) 10:1881-96. doi: 10.2741/1667

124. Choi SB, Kwon MK, Chung JW, Park JS, Chung K, Kim DW. Effects of shortterm radiation emitted by WCDMA mobile phones on teenagers and adults. BMC Public Health. (2014) 14:438. doi: 10.1186/1471-2458-14-438

125. Leach V, Weller S, Redmayne M, A. novel database of bio-effects from non-ionizing radiation. Rev Environ Health. (2018) 33:273-80. doi: 10.1515/reveh-2018-0017

126. Lushchak VI. Free radicals, reactive oxygen species, oxidative stress and its classification. Chem Biol Interact. (2014) 224:164-75. doi: 10.1016/j.cbi.2014.10.016

127. Liu B, Jian Z, Li Q, Li K, Wang Z, Liu L, et al. Baicalein protects human melanocytes from $\mathrm{H}_{2} \mathrm{O}_{2}$-induced apoptosis via inhibiting mitochondriadependent caspase activation and the p38 MAPK pathway. Free Radic Biol Med. (2012) 53:183-93. doi: 10.1016/j.freeradbiomed.2012.04.015

128. Jing M, Li YX, Zeng JZ, Huang PC, Skirzewski M, Kljakic O, et al. An optimized acetylcholine sensor for monitoring in vivo cholinergic activity. Nat Methods. (2020) 17:1139-46. doi: 10.1038/s41592-020-0953-2

Conflict of Interest: The authors declare that the research was conducted in the absence of any commercial or financial relationships that could be construed as a potential conflict of interest.

Publisher's Note: All claims expressed in this article are solely those of the authors and do not necessarily represent those of their affiliated organizations, or those of the publisher, the editors and the reviewers. Any product that may be evaluated in this article, or claim that may be made by its manufacturer, is not guaranteed or endorsed by the publisher.

Copyright $\odot 2021 \mathrm{Hu}$, Zuo and Li. This is an open-access article distributed under the terms of the Creative Commons Attribution License (CC BY). The use, distribution or reproduction in other forums is permitted, provided the original author(s) and the copyright owner(s) are credited and that the original publication in this journal is cited, in accordance with accepted academic practice. No use, distribution or reproduction is permitted which does not comply with these terms. 